\section{Kidney Blood Pressure Research}

\title{
Alterations of Renal Epithelial Glucose and Uric Acid Transporters in Fructose Induced Metabolic Syndrome
}

\author{
Hwee-Yeong Ng ${ }^{a} \quad$ Yueh-Ting Lee ${ }^{a} \quad$ Wei-Hung Kuo ${ }^{a} \quad$ Pei-Chen Huanga \\ Wei-Chia Lee ${ }^{b}$ Chien-Te Lee \\ aDivision of Nephrology, Department of Internal Medicine, Kaohsiung Chang Gung Memorial Hospital \\ and Chang Gung University College of Medicine, Kaohsiung, 'Division of Urology, Kaohsiung Chang \\ Gung Memorial Hospital and Chang Gung University College of Medicine, Kaohsiung, Taiwan
}

\section{Key Words}

Metabolic syndrome $•$ Fructose $•$ Glucose $•$ Uric acid $•$ Transporter

\begin{abstract}
Background/Aims: Hyperglycemia and hyperuricemia are two major disorders of Metabolic syndrome. Kidney plays a crucial role in maintaining the homeostasis of uric acid and glucose. The aim of the study was to examine the changes of renal glucose and uric acid transporters in animals with metabolic syndrome. Methods: Sprague-Dawley rats were fed with high fructose diet (60\%) for 3 months (FR-3) and 5 months (FR-5). At the end study, serum and urine biochemical data were compared. Gene expression and protein abundance of renal GLUT1, GLUT2, GLUT9, SGLT1, SGLT2, UAT and URAT1 was investigated by using RT-PCR and immunohistochemical staining. Results: Metabolic syndrome was induced by high-fructose diet. Systolic blood pressure and proteinuria was significantly increased in FR-5 animals. In kidney tissue, gene expression of GLUT2 and SGLT2 increased significantly in a time dependent manner. GLUT9, SGLT1 and UAT were also significantly upregulated in FR-5. Immunohistochemical study showed a significant increase of SGLT1 in both FR-3 (413.5 \pm $88.3 \%$ of control, $p<0.001)$ and FR-5 $(677.6 \pm 26.5 \%$ of control, $p<0.001)$. Also, SGLT2 protein was increased in both FR-3 $(643.1 \pm 41.3 \%$ of control, $p<0.001)$ and FR-5 $(563.3 \pm 21.7 \%$ of control, $p<0.001$ ). Fructose rich food also induced increase of UAT by nearly 5 -fold in both FR-3 and FR-5 (both p < 0.05) and more than 3-fold of GLUT-9 in FR-3 and FR-5 (both $p<0.05$ ). Conclusion: Long term high fructose diet induced metabolic syndrome with increased blood pressure and proteinuria in rats. Metabolic syndrome was associated with dual increase in renal glucose and uric acid transporters, including SGLT1, SGLT2, GLUT2, GLUT9 and UAT.
\end{abstract}




\section{Kidney Blood Pressure Research}

$\mathrm{Ng}$ et al.: Renal Glucose and Uric Acid Transporters in Metabolic Syndrome

\section{Introduction}

The prevalence and incidence of metabolic syndrome (MetS) is increasing and it has been recognized as an important contributor of diabetes as well as cardiovascular morbidity [1]. Diabetes was observed in 20 percent of patients with MetS, carrying an odd ratio around 9-10 [2]. At normal concentrations of plasma glucose, the kidneys actively reabsorb almost all filtered glucose with less than $1 \%$ excreted in the urine. Uptake of glucose in the intestine and kidneys is by active transport, mediated by members of the sodium glucose transporter (SGLT) family. SGLT1 and SGLT2 are responsible for glucose reabsorption in the proximal tubules of the kidneys [3]. Increased expression of SGLT2 has been demonstrated in experimental diabetic animals [4]. Regulation of SGLT2 is largely dependent on glycemiainduced activation of protein kinase $\mathrm{C}$ with resultant reactive oxygen species. Furthermore, angiotensin II by combining with epidermal growth factor can also modulate the SGLT2 [4]. In recent decade, SGLT2 inhibitors have become available and are listed as therapeutic option for the treatment of diabetes mellitus [5]. In MetS, little information is available regarding the alteration of SGLT1 and SGLT2.

Hyperuriecemia is another phenomenon in patients with MetS [6]. It is well-known that hyperuricemia is associated with increased risk of cardiovascular disease and also the development of chronic kidney disease [7]. The underlying cause of uric acid-associated complication is mostly via its direct effect on vasculature $[8,9]$. Hyperuricemia is associated with increased oxidative stress and inflammation. In experimental animals, hyperuricemia was associated with activation of intra-renal RAS with subsequent renal pathology [10]. The kidney also plays a vital role in uric acid homeostasis. In normal condition, about two-thirds of urate is excreted via the kidney. Most of the filtered urate is re-absorbed in proximal tubule via apical URAT1 (encoded by SLC22A12 gene), the major influx transporter [11]. Other transporters such as organic anion transporter (OAT)-10 and OAT4, UAT, NPT and ABCG2, ABCC4 are also considered as the gates for uric acid reabsorption [12]. On the basolateral site, the GLUT9 (SLC2A9) is the principal transporter responsible for extrusion of uric acid into circulation.

Fructose is commonly found in added sugar in our food, in the form of high-fructose corn syrup and sucrose [13].. Increase fructose consumption promotes a serial of metabolic changes, including hyperuricemia, hypertriglyceridemia, obesity as well as metabolic syndrome. Unlike glucose, the metabolism of fructose is not negatively controlled by plasma fructose [14]. In our study, high fructose diet was used to set up MetS animal model. We then investigated the changes of glucose and uric acid transporters in the kidney to evaluate the renal involvement in MetS.

\section{Materials and Methods}

\section{Animal Experiments}

Animal protocols were approved by the Institutional Animal Care and Use Committee (IACUC) of Kaohsiung Chang-Gung Memorial Hospital, and all animal procedures were performed according to the IACUC policy (Permit Number: 2016031701).

Adult male Sprague-Dawley rats weighting 180-200 g were used for this experiment. The animals were maintained under a constant $12 \mathrm{~h}$ photoperiod at temperatures between 21 and $23{ }^{\circ} \mathrm{C}$. The animals were allowed free access to water and selected food. They were allocated to control and fructose diet groups. Fructose diet group were fed with a fructose-rich diet (60\% fructose diet, Harlan Teklad, Madison, WI) for 3 months (FR-3, $n=8$ ) or 5 months (FR-5, $n=8)$, whereas control animals $(n=8)$ received standard rat chow for 1 month. Body weight was measured weekly until end of study. At the end of study, $24 \mathrm{~h}$ urine samples were collected from the animals using individualized metabolic cages. The rats were then sacrificed and blood samples were withdrawn from the inferior vena cava for biochemical analysis. 


\section{Kidney Blood Pressure Research}

Kidney Blood Press Res 2018;43:1822-1831

\begin{tabular}{l|l}
\hline DOI: $10.1159 / 000495814$ & (c) 2018 The Author(s). Published by S. Karger AG, Basel
\end{tabular}

Published onlıne: 8 December 2018

www.karger.com/kb
Biochemical Assay
and Blood Pressure

Measurement

Serum or urinary creatinine, electrolytes, uric acid, sugar and insulin levels were measured by using the SYNCHRON CX DELTA system [Beckman, Fullerton, CA, USA] according to manufacturer's operating protocol. Urinary excretion of protein was presented as ratio of urine total protein to creatinine (mg/gm). Urinary uric acid excretion was calculated as ratio of uric acid divided by creatinine ( $\mathrm{mg} / \mathrm{mg})$. Blood pressure was measured by indirect tailcuff method (Visitech BP2000, Visitech Systems, Apex, NC, USA). Data of three consecutive measurements were recorded and then averaged for each animal.

\section{Gene Expression Study}

Total RNA was extracted from the kidney tissue using a Total RNA Mini kit following the manufacturer's instructions, and spectrophotometry at a wavelength of $260 \mathrm{~nm}$ was then used to detect total RNA concentrations. RNA was stored at $-80{ }^{\circ} \mathrm{C}$ until use. A total of $1 \mu \mathrm{g}$ RNA of each sample was reversetranscribed using a First Strand cDNA Synthesis Kit. Real-time PCR was performed using the Light Cycler instrument with LightCycler $₫$ TaqMan $₫$ Master, Universal ProbeLibrary Probe and primers of the target gene. The results of this study were normalized with housekeeping gene $\beta$-actin. The levels of mRNA expression were presented as the ratio of each mRNA to $\beta$-actin mRNA (Table 1).

\section{Immunohistochemistry study}

Immunohistochemistry study was performed using the streptavidin-biotin complex method (TAHC02D kit, Biotna, Kaohsiung, Taiwan). Paraffin-embedded fixed tissue sections (4 $\mu \mathrm{m})$ were deparaffinized with xylene, and dehydrated with ethanol. Antigen retrieval was carried out with $10 \mathrm{mM}$ citrate buffer (pH 6.0) twice for 5 min microwave treatment. The sections were incubated with $3 \% \mathrm{H}_{2} \mathrm{O}_{2}$ methanol for 10 min, and then incubated with $10 \%$ serum for $30 \mathrm{~min}$ at room temperature. Then, anti-SGLT1 (1:50, Abcam, Cambridge, UK), SGLT2 (1:50, Biorbyt, Cambridge, UK), GLUT 9 (1:100, Merck Millipore, Billerica, MA, USA), UAT (1:25, Abbiotec, San Diego, CA, USA), URAT1(1:100, Abbiotec, San Diego, CA, USA) antibody was added, and incubated at $4^{\circ} \mathrm{C}$ overnight. The sections were incubated with the secondary antibody at room temperature for $30 \mathrm{~min}$, and then with peroxidase-conjugated streptavidin at $37^{\circ} \mathrm{C}$ for $30 \mathrm{~min}$. The expression of proteins was visualized using 3, 3'-diaminobenzidine tetrahydrochloride at a concentration of $30 \mathrm{mg} / \mathrm{mL}$, containing $0.03 \% \mathrm{H}_{2} \mathrm{O}_{2}$. All sections were photographed under light microscopy (x400) with digital camera (DN100, E-600, Nikon; Tokyo, Japan). Immunostaining-positive areas were determined using Adobe Photoshop, and quantified in 20 random fields per section using NIH Image 1.62.

\section{Statistical analysis}

Data analysis was performed with SPSS Statistics version 17 (IBM, Armonk, NY, USA). Results are expressed as mean $\pm S E$. Student t-test was used to analyze the difference of mean values between two groups. Comparison among different groups was performed by using one-way analysis of variance (ANOVA), and then examined by least significance difference (LSD) test. A $p$ value $<0.05$ is considered to be statistically significant. A $p$ value $<0.05$ is considered to be significant. 


\section{Kidney Blood Pressure Research}

\section{Results}

\section{Laboratory Data}

Table 2 demonstrates the laboratory data of study animals. Animals fed with fructose rich diet had significant higher fasting sugar in FR-3 (94.6 \pm 6.7 vs. $83.0 \pm 1.4 \mathrm{mg} / \mathrm{dL}, p<0.05$ ) and FR-5 animals (134.8 \pm $11.4, p<0.05$ ). Compared to control group, uric acid and triglyceride levels were similar in FR-3 but were significantly increased in FR-5. In FR-5, serum uric acid was $1.7 \pm 0.7 \mathrm{mg} / \mathrm{dL}$ (vs. $0.7 \pm 0.4 \mathrm{mg} / \mathrm{dL}$ of control, $p<0.05$ ) and triglyceride was $334.0 \pm 220.6 \mathrm{mg} / \mathrm{dL}$ (vs. 70.3 $\pm 14.5 \mathrm{mg} / \mathrm{dL}$ of control, $p<0.05$ ). A trend of increasing serum total cholesterol levels was observed in rats fed with fructose rich diet. Serum cholesterol was significant higher than control in FR-5. Serum creatinine, sodium and potassium did not differ among three groups. The creatinine clearance was highest in FR-3 than other groups. And no significant difference was noted between FR-5 and control groups. Proteinuria was significantly higher in animals after feeding with high fructose diet for 5 months. Urine excretion of uric acid was increased in FR-3 and FR-5 groups when compared to control. Regarding blood pressure, significant higher blood pressure was noted in FR-5 group when compared to control and also FR-3.

\section{Gene Expression Study}

Fig. 1 shows the changes of glucose and uric acid transporters after the experiment. Gene expression of GLUT1 was comparable between FR-3 group and control (Fig. 1a). In renal tissue of FR-5 group, GLUT1 reduced significantly ( $55 \pm 6.5 \%$ of control, $p<0.001$ ). But GLUT2 increased significantly in fructose-rich groups. Renal expression of GLUT2 increased approximately 2.5 fold ( $258.9 \pm 45.2 \%$ of control, p<0.001, Fig. 1b) in FR-3 group and 4.8 fold (481.4 $\pm 26.2 \%$ of control, $p<0.001$ ) in FR-5 group. There was no significant alteration of GLUT9 in FR-3 group but a higher expression of GLUT9 was noted in FR-5 animals (169.8 $\pm 12.1 \%$ of control, p<0.05, Fig. 1c). Expression SGLT1 was higher in FR-3 (260.8 $\pm 41.1 \%$, p $<0.001)$ and in FR-5 groups $(189.1 \pm 47.3 \%$ p $<0.05$, Fig. $1 d)$ when compared to control group. There was also a significant increase of gene expression of SGLT2 in both FR-3 (233.5 $\pm 53.3 \%$ of control, $\mathrm{p}<0.05)$ and FR-5 groups $(323.0 \pm 63.9 \%$ of control, $\mathrm{p}<0.05$, Fig. 1e). In additional, fructose-rich diet induced a profound upregulation of renal UAT expression. Compared to control group, gene expression of UAT was approximately 5 fold higher in FR-3 group (498.8 $\pm 25.3 \%$ of control, $\mathrm{p}<0.001)$ and 5.4 fold higher in FR-5 group $(539.7 \pm 33.1 \%$ of control, p $<0.001$, Fig. 1f). No change of URAT1 gene expression was detected among the groups (Fig. 1g).

\section{Immunoblotting}

In kidney sections, SGLT1 and SGT2 were mainly expressed in the proximal tubules (Fig. 2a). Compared to control group, renal protein abundance of SGLT1 were increased progressively along with time of fructose ingestion. There was also a significant increase of SGLT1 protein in both FR-3 (413.5 $\pm 88.3 \%$ of control, p<0.001) and FR-5 $(677.6 \pm 26.5 \%$ of control, $p<0.001$ and $p<0.05$ vs. FR-3, Fig. 2a). For SGLT2, the protein was upregulated in both FR-3 (643.1 $\pm 41.3 \%$ of control, p<0.001) and FR-5 groups $(563.3 \pm 21.7 \%$ of control,
Table 2. Laboratory data of the animals. Abbreviations: Cr: creatinine; Na: sodium; K: potassium. ${ }^{*}$ p $<0.05$ vs. control; \#p<0.05 vs. FR-3

\begin{tabular}{lccc}
\hline Parameter & Control & FR-3 & FR-5 \\
\hline Body weight (g) & $243.7 \pm 9.6$ & $547.2 \pm 25.6^{*}$ & $596.0 \pm 31.6^{*}$ \\
Systolic blood pressure (mmHg) & $148.6 .0 \pm 13.7$ & $156.9 \pm 9.8$ & $165.2 \pm 10.1^{*}$ \\
Diastolic blood pressure (mmHg) & $76.7 \pm 10.2$ & $80.1 \pm 9.5$ & $108.5 \pm 25.7^{*}$ \\
Serum glucose (mg/dL) & $83.0 \pm 1.4$ & $94.6 \pm 6.7^{*}$ & $134.8 \pm 11.4^{* \#}$ \\
Serum uric acid (mg/dL) & $0.72 \pm 0.43$ & $0.81 \pm 0.24$ & $1.72 \pm 0.69^{* \#}$ \\
Serum total cholesterol (mg/dL) & $72.8 \pm 2.1$ & $84.6 \pm 22.5$ & $109.4 \pm 33.3^{*}$ \\
Serum triglyceride (mg/dL) & $70.3 \pm 14.5$ & $130.0 \pm 54.1^{*}$ & $334.0 \pm 220.6^{*}$ \\
Serum Cr (mg/dL) & $0.30 \pm 0.02$ & $0.38 \pm 0.04^{*}$ & $0.37 \pm 0.05^{*}$ \\
Serum Na (mg/dL) & $140.8 \pm 1.6$ & $141.6 \pm 3.9$ & $143.0 \pm 3.1$ \\
Serum K (mg/dL) & $4.1 \pm 0.6$ & $3.7 \pm 0.3$ & $3.8 \pm 0.2$ \\
Daily urine amount (mL) & $20.1 \pm 7.8$ & $21.8 \pm 6.8$ & $23.4 \pm 14.4$ \\
Urine Cr (mg/dL) & $47.8 \pm 17.2$ & $99.2 \pm 27.6^{*}$ & $65.1 \pm 23.4^{\#}$ \\
Cr clearance (mL/min) & $1.9 \pm 0.4$ & $3.7 \pm 0.6^{*}$ & $2.5 \pm 1.2^{\#}$ \\
Urine protein to Cr ratio (mg/g) & $515.2 \pm 175.2$ & $451.3 \pm 163.8$ & $888.6 \pm 547.9^{* \#}$ \\
Urine Na to Cr ratio(mg/mg) & $5.6 \pm 0.6$ & $5.1 \pm 1.0$ & $5.5 \pm 0.6$ \\
Urine K to Cr ratio (mg/mg) & $1.8 \pm 0.5$ & $1.1 \pm 0.2$ & $1.0 \pm 0.3$ \\
Urine uric acid to Cr ratio (mg/mg) & $0.18 \pm 0.07$ & $0.24 \pm 0.04^{*}$ & $0.24 \pm 0.02^{*}$ \\
Uric acid fractional excretion & $0.10 \pm 0.05$ & $0.50 \pm 0.34^{*}$ & $0.33 \pm 0.29$ \\
\hline
\end{tabular}




\section{Kidney Blood Pressure Research}

Fig. 1. Gene expression of GLUT family (a-c), SLGT family (d-e) and urate transporters (f-g) in control and fructose-rich diet groups. ${ }^{*} \mathrm{p}<0.05$ vs. control; ${ }^{* *} \mathrm{p}<0.001$ vs. control; \# $\mathrm{p}<0.05$ vs. FR-3; \#\# $\mathrm{p}<0.001$ vs. FR-3. (a)

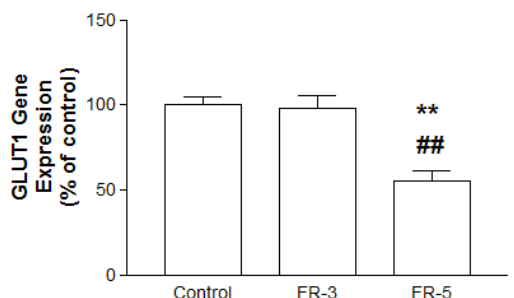

(c)

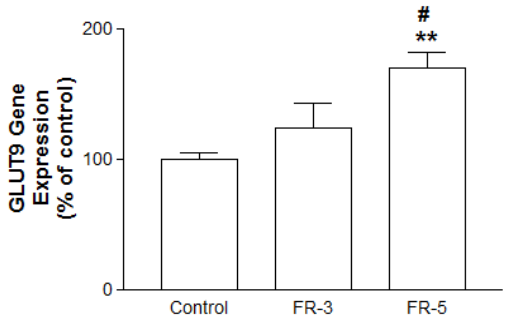

(e)
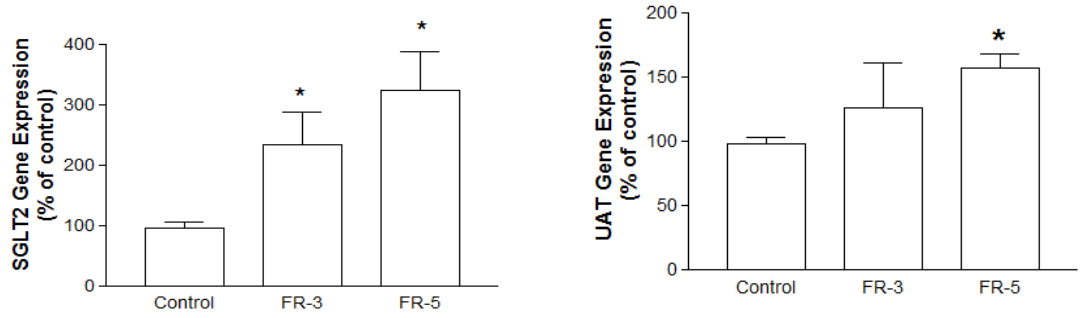

(g)

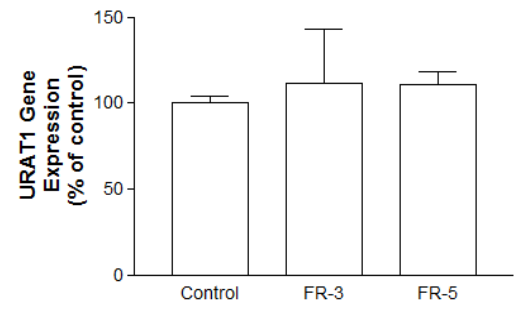

p<0.001, Fig. 2b). As for uric acid transporters, both GLUT9 and UAT were increased after feeding with high fructose diet. Expression of renal GLUT9 was $280.6 \pm 13.5 \%$ of control $(p<0.001)$ in FR-3 and $362.3 \pm 26.5 \%$ of control in FR-5 $(p<0.001$, Fig. 3a). There was a nearly 5-fold higher of UAT in FR-3 and FR-5 groups when compared to control group (both $\mathrm{p}<0.001$, Fig. 3b). We found that protein abundance of URAT1 was slightly increased in FR-3 than control (143.5 $\pm 7.8 \%$ vs. $100.0 \pm 13.1 \%$, p <0.05, Fig. 3c). With longer duration of high fructose feeding, the protein abundance of URAT1 in FR-5 was not different from control $(127.1 \pm 7.0 \%$ of control, $\mathrm{p}>0.05)$. 


\section{Kidney Blood Pressure Research}

\section{Discussion}

In this study, we observed that fructose rich diet induced features of metabolic syndrome, including hypertension, high fasting blood sugar, hyperuricemia, hypercholesterolemia and hypertri-glyceridemia. Furthermore, manifestations became more obvious as experiment continued. Significant increased creatinine clearance was found in FR-3. After 5 months of high fructose diet feeding, proteinuria developed and a declined creatinine clearance than FR-3 was noted. These findings disclosed the temporal deleterious effect of MetS on kidney function, similar to the serial change of diabetic nephropathy. In the kidney, we found upregulation of glucose transporters, including GLUT2, GLUT9, SGLT1 and SGLT2. Renal uric acid handling was also affected with increased expression of UAT and GLUT9.

Both glucose and fructose are monosaccaride but there are large differences in metabolism and renal handling [15]. Filtration rate of fructose is higher than glucose in the renal tubule. In the renal tubules, filtrated glucose is reabsorbed via SGLT1 and SGLT2 while fructose is reuptaken mainly through GLUT2 and GLUT5 [16]. In the liver, fructose induces de novo lipogenesis and hypertriglycemia [17] but isocaloric glucose load increases dyslipidemia in a relatively lower degree [18]. Unlike glucose, fructose has low glycemic index but it causes insulin resistance in the liver and
Kidney Blood Press Res 2018;43:1822-1831

\begin{tabular}{l|l}
\hline DOI: 10.1159/000495814 & $\odot 2018$ The Author(s). Published by S. Karger AG, Basel
\end{tabular}

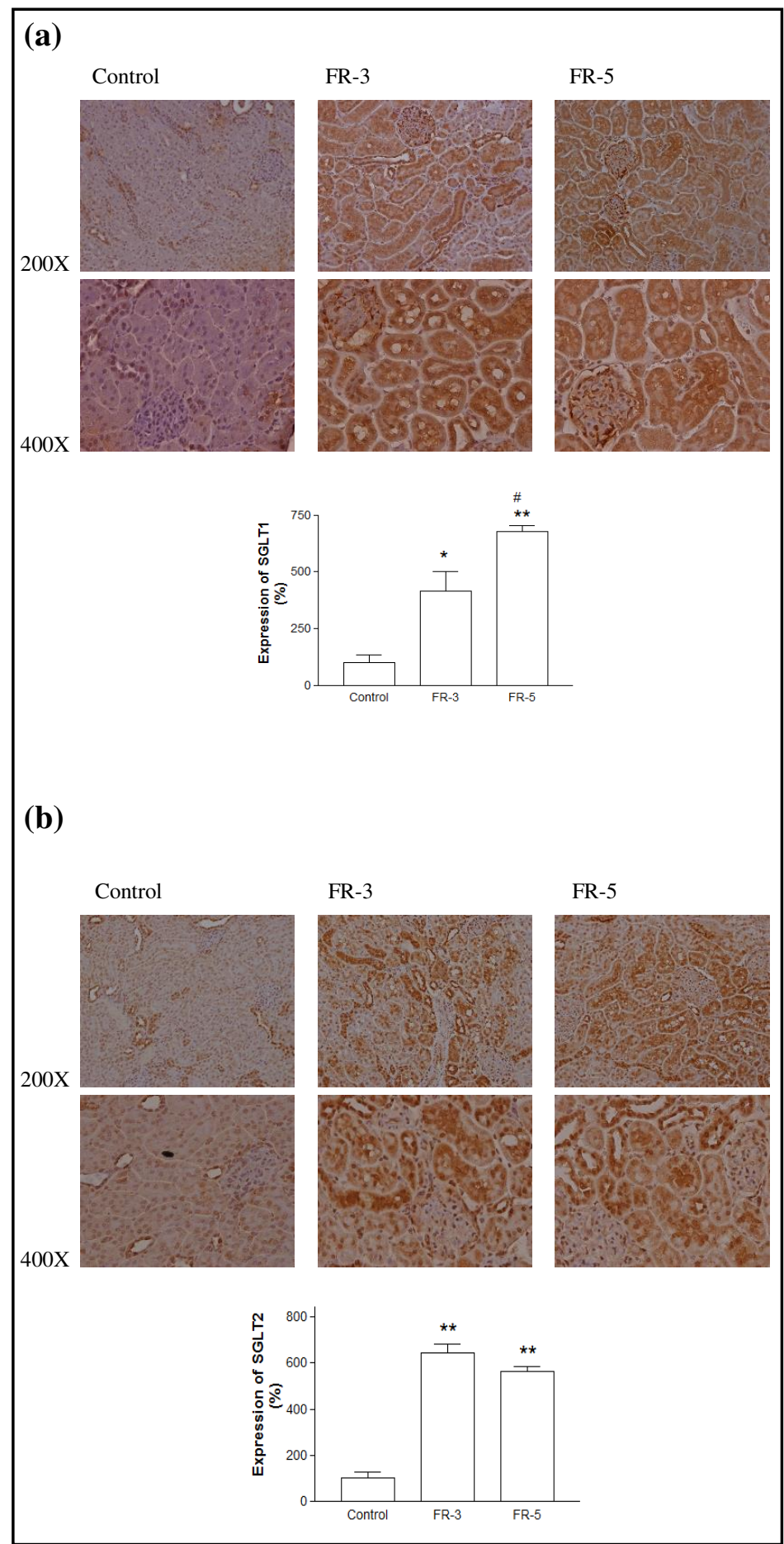

Fig. 2. Protein expression of SGLT1 (a) and SGLT2 (b) in renal sections. Both SGLT1 and SGLT2 were upregulated significantly in animals fed with high fructose, including FR-3 and FR-5.* p<0.05 vs. control; ** p $<0.001$ vs. control; \# p $<0.05$ vs. FR-3; \#\# p<0.001 vs. FR-3. 


\section{Kidney Blood Pressure Research}

adipose tissue in the long term [19]. Despite the disparities, addition of glucose to fructose ingestion facilitates intestinal fructose absorption [20]. In our experiment, we found that chronic fructose consumption upregulated not only GLUT2, GLUT9 but also SGLT1 and SGLT2, implying that fructose may also enhance glucose reabsorption simultaneously. Our finding provides a molecular insight that MetS was associated with increased glucose transport that precedes the full manifestation of diabetes. These alterations in renal epithelial transport develop earlier than diabetes.

Significant increase in blood pressure was observed in FR-5 animals. Fructose induced hypertension by increasing vasoconstrictors such as endothelin-1 and angiotensin II [21] and upregulating renal sodiumhydrogen exchanger 3 (ENaC) [22]. Nevertheless, Nizar et al. found no increased $\mathrm{ENaC}$ activity in high fat-fed mouse model of metabolic syndrome and blocking ENaC with amiloride also did not reverse anti-natriuresis or ENaC activity [23]. In this study, we found that a significant upregulation of SGLT1 and SGLT2 in renal tubule. Thus, we provided another additional explanation that sodium retentive mechanism is more extensive in MetS as noted in alterations in proximal tubule in

\section{Kidney Blood Press Res 2018;43:1822-1831}

\begin{tabular}{l|c|c|c|}
\hline DOI: 10.1159/000495814 & C 2018 The Author(s). Published by S. Karger AG, Basel \\
\hline
\end{tabular} Published online: 8 December 2018 www.karger.com $/ \mathrm{kbr}$

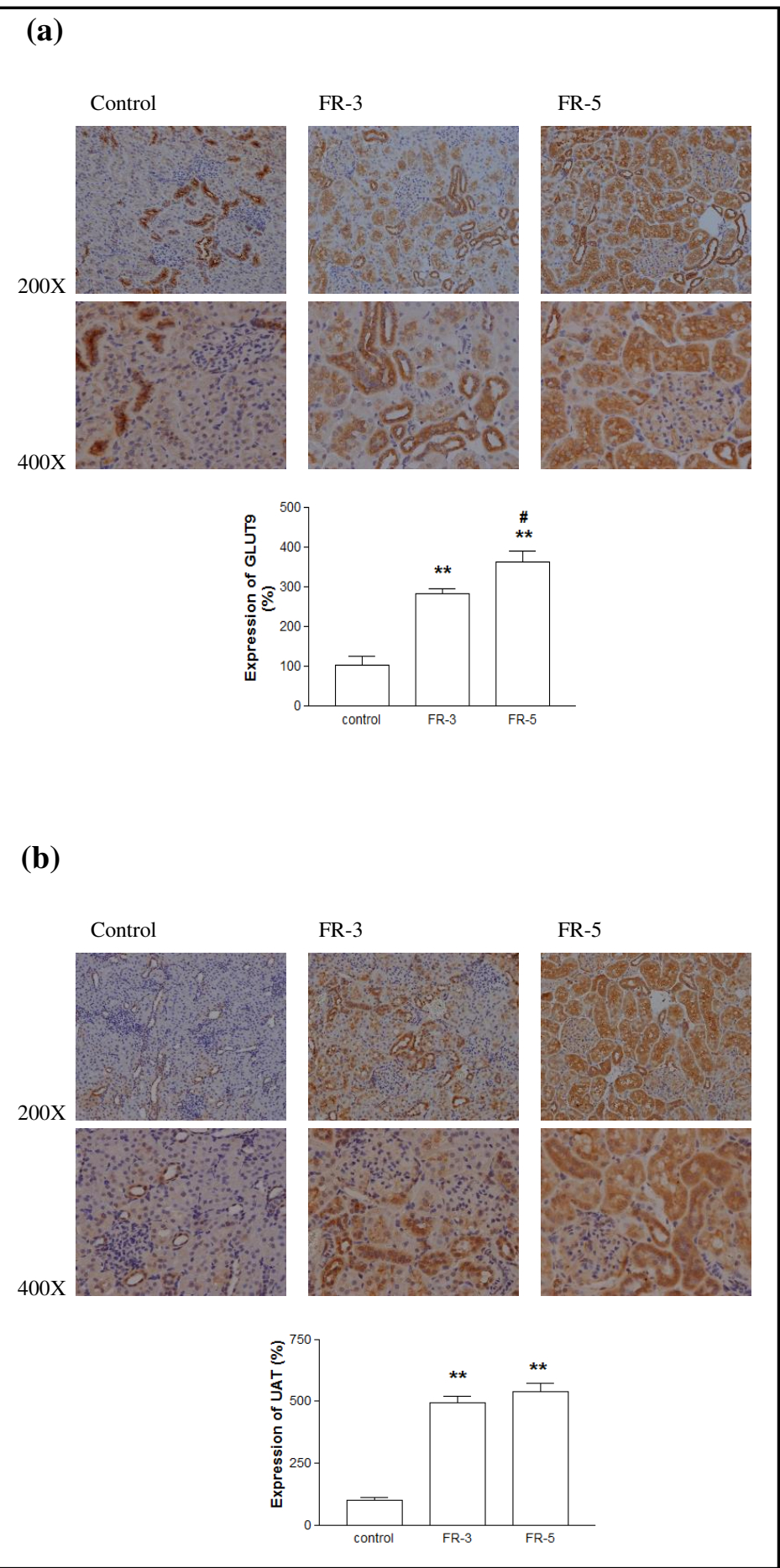

Fig. 3. Protein expression of GLUT9 (a), UAT (b) and URAT1(c) in renal sections. GLUT9 increased significantly in a time dependent manner. Significant higher expression of UAT was noted in both FR-3 and FR-5. URAT1 increased modestly but significant in FR-3 but was similar to control group in FR-5. ${ }^{*} \mathrm{p}<0.05$ vs. control; ${ }^{* *} \mathrm{p}<0.001$ vs. control; \# $\mathrm{p}<0.05$ vs. FR-3; \#\# $\mathrm{p}<0.001$ vs. FR-3. 


\section{Kidney Blood Pressure Research}

additional to collecting tubule. In clinical study, SGLT2 inhibitors exerts antihypertensive and antinatriuretic effect [24], indicating the role of SGLT in the pathophysiology of insulin resistance related hypertension.

Fructose is metabolized in the liver and consumes intracellular adenosine triphosphate. Metabolism of adenosine triphosphate results in the synthesis of uric acid as a byproduct [25]. The kidney contributes to uric acid homeostasis by filtration, secretion and reabsorption [26]. In our study, serum uric acid was similar to control group in FR-3 animals but urinary excretion of uric acid was increased. The upregulation of UAT, GLUT9 may representa response to increased filtered load of uric acid. As ingestion of fructose continued, the compensation mechanism was disrupted. Serum uric acid increased significantly in FR-5 group while renal expression of UAT and GLUT9 was higher than FR-3 group with comparable urinary uric acid excretion.

In contrast to UAT that is uniquely expressed at the apical membrane, GLUT9 is more frequently known as major entry of urate at the basolateral aspect of proximal tubule. Recently, GLUT9 has been demonstrated that it also expressed at the apical membrane with different alternatively spliced variants [27]. Apart from being a urate transport, GLUT9 is also a minor fructose and glucose transporter [28]. GLUT9 is also involved in glucose metabolism by affecting glucose-sensing in pancreatic $\beta$-cells [29]. The relationship between hyperuricemia and diabetes is complex and close. It has been reported that increased incidence of type 2 diabetes by $6 \%$ per $1 \mathrm{mg} / \mathrm{dL}$ increment in serum uric acid level [30]. Taken together, fructose/uric acid are probably the missing link of gap between the diabetes and MetS [31]. The GLUT9 is the central player at least in the renal tissue.

\section{Conclusion}

Chronic high fructose consumption induced MetS and increased blood pressure and proteinuria in rats. Renal handling of glucose and urate was dysregulated by alterations of epithelial transporters, including SGLT1, SGLT2, GLUT2, GLUT9, and UAT.

\section{Acknowledgements}

This work was supported by the research grant from Chang Gung Memorial Hospital, Kaohsiung Medical Center, Kaohsiung, Taiwan (CMRPG8F0531).

\section{Disclosure Statement}

The authors declare no conflicts of interest.

\section{References}

1 Raimundo M, Lopes JA: Metabolic syndrome, chronic kidney disease, and cardiovascular disease: a dynamic and life-threatening triad. Cardiol Res Pract 2011;2011:747861.

72 Aschner P: Metabolic syndrome as a risk factor for diabetes. Expert Rev Cardiovasc Ther 2010;8:407-412.

-3 Abdul-Ghani MA, Norton L, Defronzo RA: Role of sodium-glucose cotransporter 2 (SGLT 2) inhibitors in the treatment of type 2 diabetes. Endocr Rev 2011;32:515-531.

4 Lee YJ, Lee YJ, Han HJ: Regulatory mechanisms of $\mathrm{Na}(+)$ /glucose cotransporters in renal proximal tubule cells. Kidney Int Suppl 2007;72:S27-S35. 


\section{Kidney \\ Blood Pressure Research}

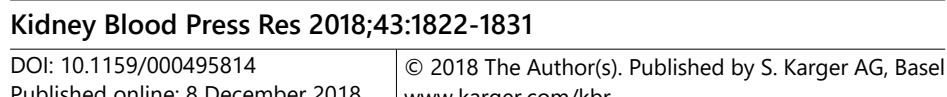

\begin{tabular}{l|l} 
DOI: 10.1159/000495814 & $\begin{array}{l}\text { C } 2018 \text { The Author(s). } \\
\text { www.karger.com/kbr }\end{array}$ \\
Published onlIne: 8 December 2018 & wwor.
\end{tabular}

$\mathrm{Ng}$ et al.: Renal Glucose and Uric Acid Transporters in Metabolic Syndrome

5 Musso G, Gambino R, Cassader M, Pagano G: A novel approach to control hyperglycemia in type 2 diabetes: sodium glucose co-transport (SGLT) inhibitors: systematic review and meta-analysis of randomized trials. Ann Med 2012;44:375-393.

6 Ishizaka N, Ishizaka Y, Toda, E, Nagai R, Yamakado M: Association between serum uric acid, metabolic syndrome, and carotid atherosclerosis in Japanese individuals. Arterioscler Thromb Vasc Biol 2005;25:1038-1044.

7 Chaudhary K, Malhotra K, Sowers J, Aroor A.: Uric Acid - key ingredient in the recipe for cardiorenal metabolic syndrome. Cardiorenal Med 2013;3:208-220.

-8 Liang WY, Zhu XY, Zhang JW, Feng XR, Wang YC, Liu ML: Uric acid promotes chemokine and adhesion molecule production in vascular endothelium via nuclear factor-kappa B signaling. Nutr Metab Cardiovasc Dis 2015;25:187-194.

\9 Kanellis J, Watanabe S, Li JH, Kang DH, Li P, Nakagawa T, Wamsley A, Sheikh-Hamad D, Lan HY, Feng L, Johnson RJ: Uric acid stimulates monocyte chemoattractant protein-1 production in vascular smooth muscle cells via mitogen-activated protein kinase and cyclooxygenase-2. Hypertension 2003;41:12871293.

10 Sánchez-Lozada LG, Tapia E, Avila-Casado C, Soto V, Franco M, Santamaría J, Nakagawa T, Rodríguez-Iturbe B, Johnson RJ, Herrera-Acosta J: Mild hyperuricemia induces glomerular hypertension in normal rats. Am J Physiol Renal Physiol 2002; 283:F1105-F1110.

11 Stamp LK, Chapman PT: Urate-lowering therapy: current options and future prospects for elderly patients with gout. Drugs Aging 2014;31:777-786.

12 Mount DB: The kidney in hyperuricemia and gout. Curr Opin Nephrol Hypertens 2013;22:216-223.

13 Elliott S, Keim NL, Stern JS, Teff K, Havel PJ: Fructose, weight gain, and the insulin resistance syndrome. Am J Clin Nutr 2002;76:911-922.

$\checkmark 14$ Mayes PA: Intermediary metabolism of fructose. Am J Clin Nutr 1993;58:754S-765S.

15 Ares GR, Ortiz PA: Direct renal effects of a fructose-enriched diet: interaction with high salt intake. Am J Physiol Regul Integr Comp Physiol 2015;309:R1078-R1081.

16 Lanaspa MA, Tapia E, Soto V, Sautin Y, Sánchez-Lozada LG: Uric acid and fructose: potential biological mechanisms. Semin Nephrol 2011;31:426-432.

17 Havel PJ: Dietary fructose: implications for dysregulation of energy homeostasis and lipid/carbohydrate metabolism. Nutr Rev 2005;63:133-157.

18 Bidwell AJ: Chronic Fructose Ingestion as a Major Health Concern: Is a Sedentary Lifestyle Making It Worse? A Review. Nutrients 2017;9:E549.

19 Rutledge AC, Adeli K: Fructose and the metabolic syndrome: pathophysiology and molecular mechanisms. Nutr Rev 2007;65:S13-S23.

20 Gonzalez JT, Fuchs CJ, Betts JA, van Loon LJ: Glucose Plus Fructose Ingestion for Post-Exercise RecoveryGreater than the Sum of Its Parts? Nutrients 2017;9:E344.

-21 Tran LT, Yuen VG, McNeill JH: The fructose-fed rat: a review on the mechanisms of fructose-induced insulin resistance and hypertension. Mol Cell Biochem 2009;332:145-159.

-22 Queiroz-Leite GD, Crajoinas RO, Neri EA, Bezerra CN, Girardi AC, Rebouças NA, Malnic G: Fructose acutely stimulates NHE3 activity in kidney proximal tubule. Kidney Blood Press Res 2012;36:320-334.

-23 Nizar JM, Dong W, McClellan RB, Labarca M, Zhou Y, Wong J, Goens DG, Zhao M, Velarde N, Bernstein D, Pellizzon M, Satlin LM, Bhalla V: Na+-sensitive elevation in blood pressure is ENaC independent in dietinduced obesity and insulin resistance. Am J Physiol Renal Physiol 2016310:F812-F820.

-24 Lytvyn Y, Bjornstad P, Udell JA, Lovshin JA, Cherney DZI: Sodium Glucose Cotransporter-2 Inhibition in Heart Failure: Potential Mechanisms, Clinical Applications, and Summary of Clinical Trials. Circulation 2017; 136:1643-1658.

25 Hallfrisch J: Metabolic effects of dietary fructose. FASEB 1990;4:2652-2660.

-26 Jalal DI: Hyperuricemia, the kidneys, and the spectrum of associated diseases: a narrative review. Curr Med Res Opin 2016;32:1863-1869.

27 Augustin R, Carayannopoulos MO, Dowd LO, Phay JE, Moley JF, Moley KH: Identification and characterization of human glucose transporter-like protein-9 (GLUT9): alternative splicing alters trafficking. J Biol Chem 2004;279:16229-16236. 


\section{Kidney

28 Carayannopoulos MO, Schlein A, Wyman A, Chi M, Keembiyehetty C, Moley KH: GLUT9 is differentially expressed and targeted in the preimplantation embryo. Endocrinology 2004;145:1435-1443.

29 Evans SA, Doblado M, Chi MM, Corbett JA, Moley KH: Facilitative glucose transporter 9 expression affects glucose sensing in pancreatic beta-cells. Endocrinology 2009;150:5302-5310.

-30 Lv Q, Meng XF, He FF, Chen S, Su H, Xiong J, Gao P, Tian XJ, Liu JS, Zhu ZH, Huang K, Zhang C: High serum uric acid and increased risk of type 2 diabetes: a systemic review and meta-analysis of prospective cohort studies. PLoS One 2013;8:e56864.

-31 Kanbay M, Jensen T, Solak Y, Le M, Roncal-Jimenez C, Rivard C, Lanaspa MA, Nakagawa T, Johnson RJ: Uric acid in metabolic syndrome: From an innocent bystander to a central player. Eur J Intern Med 2016;29:3-8. 